Hydrology and Earth System Sciences, 7(6), 937-948 (2003) C EGU

\title{
Microwave radiometric measurements of soil moisture in Italy
}

\author{
G. Macelloni, S. Paloscia, P. Pampaloni, E. Santi and M. Tedesco \\ Institute of Applied Physics, CNR-IFAc, Via Panciatichi 64, 50127 Firenze, Italy \\ Email for corresponding author: s.paloscia@ifac.cnr.it
}

\begin{abstract}
Within the framework of the MAP and RAPHAEL projects, airborne experimental campaigns were carried out by the IFAC group in 1999 and 2000 , using a multifrequency microwave radiometer at L, C and X bands $(1.4,6.8$ and $10 \mathrm{GHz})$. The aim of the experiments was to collect soil moisture and vegetation biomass information on agricultural areas to give reliable inputs to the hydrological models. It is well known that microwave emission from soil, mainly at L-band $(1.4 \mathrm{GHz})$, is very well correlated to its moisture content. Two experimental areas in Italy were selected for this project: one was the Toce Valley, Domodossola, in 1999, and the other, the agricultural area of Cerbaia, close to Florence, where flights were performed in 2000. Measurements were carried out on bare soils, corn and wheat fields at different growth stages and on meadows. Ground data of soil moisture (SMC) were collected by other research teams involved in the experiments. From the analysis of the data sets, it has been confirmed that L-band is well related to the SMC of a rather deep soil layer, whereas C-band is sensitive to the surface SMC and is more affected by the presence of surface roughness and vegetation, especially at high incidence angles. An algorithm for the retrieval of soil moisture, based on the sensitivity to moisture of the brightness temperature at C-band, has been tested using the collected data set. The results of the algorithm, which is able to correct for the effect of vegetation by means of the polarisation index at $\mathrm{X}$-band, have been compared with soil moisture measurements in the ground. Finally, the sensitivity of emission at different frequencies to the soil moisture profile was investigated. Experimental data sets were interpreted by using the Integral Equation Model (IEM) and the outputs of the model were used to train an artificial neural network to reproduce the soil moisture content at different depths.
\end{abstract}

Keywords: microwave radiometry, soil moisture mapping, river basins, vegetative biomass, neural networks

\section{Introduction}

The ever-increasing interest in meteorological events and climate changes has led to a focus on the study of hydrological processes and their dynamics. Soil moisture is a very important parameter of the hydrological cycle, able to influence runoff during precipitation events. It plays an important role in flood prediction as an initial condition of the catchment system and as a soil state variable influencing evapotranspiration fluxes. Numerous models have been developed to analyse the water balance mechanisms for agricultural and meteorological purposes, as in flood and weather prediction and climate dynamic studies. All these models require knowledge of the soil moisture as an input parameter.

Soil moisture values are usually obtained by meteorological data or provided by in situ methods; however, the use of hydrological models for extending the forecast of soil moisture over larger areas is not easy, and depends on the homogeneity of the selected areas and on the information available on them (soil properties, such as hydraulic characteristics, and permeability, together with meteorological and climatological data, etc.). Moreover, direct field measurements allow the retrieval of a precise estimate of SMC in a very concentrated spot and a lot of samples must be collected to give a representative sampling of the area examined.

Thus, the possibility of using remote sensing to monitor a large area rapidly and to measure integrated values of some geophysical parameters on both global and regional scales, instead of merely at several sparse points, is very interesting. Another advantage of remote sensing techniques is the possibility of checking the evolution in time of these parameters, thus improving hydrological model predictions by using repeated satellite passages. The confirmed sensitivity of the electromagnetic radiation in the microwave band to the moisture of soil and vegetation can be an 
important tool in global and local scale monitoring of the soil.

Some field experiments, focused on the observation of soil moisture conditions using microwave radiometers, were carried out in the Toce river valley (Lago Maggiore area) and on the Cerbaia agricultural area (Tuscany), within the framework of the Mesoscale Alpine Programme (MAP) and Runoff and Atmospheric Processes for flood HAzard forEcasting and controL project (RAPHAEL). MAP and RAPHAEL are both international and interdisciplinary projects devoted to the study of atmospheric and hydrological processes in mountain river basins, aimed at improving knowledge of weather and climate over complex topography, and current meteorological forecasting capabilities on the Alpine region (Bougeault and Binder, 2002; Binder and Schär, 1996; Lampart et al., 2000). The aim of the microwave measurements was to provide soil moisture and vegetation biomass estimates prior to some expected flood events, to investigate the role of soil moisture prior to flood events as an initial condition of the catchment and as a soil state variable influencing the evapotranspiration fluxes monitored with micro-meteorological stations.

\section{Microwave remote sensing techniques}

Microwave radiation is strongly influenced by the dielectric properties of the observed media, which are characterised by their complex dielectric constant. The dielectric constant is a measure of the response of the soil to an electromagnetic wave and ranges between a few units for dry matter to about 80 for free liquid water. This is the reason for the very high sensitivity of microwaves to the moisture contained in the observed bodies, depending on the water molecule's ability to align its dipole moment along an applied field.

The microwave radiation from soil can be expressed, through the Rayleigh Jeans law, by means of an equivalent ('brightness') temperature $\mathrm{T}_{\mathrm{b}}$ defined as the physical temperature of a black body having the same brightness at the wavelength to be considered. Assuming the dielectric and thermal properties of the soil to be almost homogeneous at both the horizontal and vertical scales, the brightness temperature can be related to the physical temperature of the soil through a factor $\boldsymbol{e}$ (emissivity), which takes into account the part of emission reflected at the surface $(\boldsymbol{r})$ and depends on the physical and geometrical characteristics of the soil. $T_{b}$ can be expressed as follows (Ulaby et al., 1981):

$$
\mathrm{T}_{\mathrm{b}}=(1-\boldsymbol{r}) \mathrm{T}_{\text {soil }}=\boldsymbol{e} \mathrm{T}_{\text {soil }}
$$

Since $e$ is strongly dependent on the dielectric characteristics of soil, a decrease of $\boldsymbol{e}$ from 0.95 to 0.60 can be expected in the usual range of soil moisture (from 0 to $\gg 40 \%$ ) with a consequent change of $\mathrm{T}_{\mathrm{b}}$ of about $100 \mathrm{~K}$ (and a sensitivity of $\approx 3 / 4 \mathrm{~K}$ for each $0.01 \mathrm{~g} \mathrm{~cm}^{3}$ of water). If the sensitivity of microwave sensors is higher than $0.5 \mathrm{~K}$, their ability to measure soil moisture is very accurate.

Another parameter playing an important role in microwave emission from soils is the surface soil roughness, which causes an increase in emissivity and a reduction of the sensitivity to SMC, especially at the higher frequencies (Choudhury et al., 1979; Wang et al., 1983). The definition of 'roughness' of a soil surface depends both on the surface characteristics and the observation wavelength. The main parameters used to define the statistical characteristics of the surface are the standard deviation of height $(s)$ and the correlation length $(l)$. If the wave number is defined as $\mathrm{k}=$ $2 \mathrm{p} / \lambda$, where $\lambda$ is the wavelength, a surface can be considered

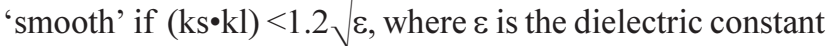
of soil (Fung 1994).

On canopy-covered fields the presence of vegetation affects the sensitivity to soil moisture, mainly at the higher frequencies, since plants absorb emission from soil and reemit their own radiation. For instance, at $10 \mathrm{GHz}$, most of the radiation upwelling from a canopy-covered soil is emitted from plants. In general, the sensitivity reduction factor to SMC measurement depends on quantity of biomass overlaying soil. Therefore, except for very light vegetation cover, a fairly accurate measurement of soil moisture under vegetated canopies requires some estimate of the biomass above the ground.

Extensive investigations were carried out to test the potential of microwave radiometers in measuring SMC and to determine the best observation parameters. Since the sensitivity of the electromagnetic emission to the soil properties depends on the observation wavelength, the frequency used is important for the retrieval of soil parameters. Although vegetation cover and surface roughness reduce the sensitivity to soil moisture, several experiments confirmed that, from an operational point of view, the best frequency for estimating soil moisture under a wide range of canopy conditions and roughness is around $1.5 \mathrm{GHz}$ (L-band, $21 \mathrm{~cm}$ wavelength) (Ulaby et al., 1983). Most research activities were performed by US (e.g. Jackson et al., 1982; Schmugge et al., 1986) and Russian (e.g. Shutko, 1982) scientists. The latter were the first to carry out large-scale aircraft investigations to test microwave radiometers in water management.

The Consiglio Nazionale delle Ricerche (CNR) in Florence (Italy) have carried out extensive experimental research on microwave emission from agricultural fields since 1980, using the IROE sensor (Instrument for Radio Observations of the Earth), composed of a set of microwave 
dual-polarised profiling radiometers, operating at L- (1.4 $\mathrm{GHz}), \mathrm{C}-(6.8 \mathrm{GHz}), \mathrm{X}-(10 \mathrm{GHz}), \mathrm{Ku}-(19 \mathrm{GHz})$ and $\mathrm{Ka}-$ $(37 \mathrm{GHz})$ bands, combined with a thermal infrared sensor (8-14 $\mu \mathrm{m})$ (Paloscia et al., 1993b; Macelloni et al., 2000).

The IROE measurements, carried out over agricultural areas both from groundbased and airborne platforms, confirmed that microwave emission from soil is very well correlated with its moisture content. At frequencies around 1.5 GHz (L-band), the sensitivity to SMC of the first 5-10 $\mathrm{cm}$ layer is fairly high, even for vegetated fields and ranges from $\approx 3.5 \mathrm{~K} / 0.01 \mathrm{~g} \mathrm{~cm}^{-3}$ for smooth bare surfaces to $\approx 1 \mathrm{~K} /$ $0.01 \mathrm{~g} \mathrm{~cm}^{-3}$, due to the effect of surface roughness and the presence of vegetation (Paloscia et al., 1993b; Pampaloni et al., 1990). C-band data can also be used in soil moisture retrieval, although this frequency is more affected by vegetation and surface roughness than the lower ones (Jackson et al., 1984). Since the presence of vegetation strongly attenuates the emission from soil at the higher frequencies, X-, Ku- and Ka-bands (10, 19 and $37 \mathrm{GHz})$ of the IROE sensor were found to be much more suitable for detecting vegetation parameters (Pampaloni and Paloscia, 1985; Paloscia and Pampaloni, 1988; Paloscia and Pampaloni, 1992).

Current research is now engaged in increasing the accuracy and reliability of the method for operational use of microwave radiometers. The main topics are the depth to which microwave radiometers sample SMC directly, and the quantification of the effects of spurious factors, such as surface roughness and vegetation cover. Moreover, the soil depth involved in the emission depends mainly on frequency and, whereas L-band is able to estimate the moisture of a relatively thick soil layer, higher frequencies are sensitive only to the moisture in soil layers closer to the surface. This leads to the hypothesis that multi- frequency observations should be able to retrieve the soil moisture profile.

In addition to the brightness temperature $T_{b}$, other parameters typically used for land investigations, besides the brightness temperature, $\mathrm{T}_{\mathrm{b}}$, are:
- the normalised temperature $\left(T_{n}\right)$, i.e. the ratio between the $T_{b}$ and the thermal infrared temperature of the surface $\left(\mathrm{T}_{\mathrm{n}}=\mathrm{T}_{\mathrm{b}} / \mathrm{T}_{\mathrm{ir}}\right)$,

- the Polarization Index (PI), i.e. the difference between the $\mathrm{T}_{\mathrm{b}}$ in vertical and horizontal polarisation normalised to the average $\left(P I=\left(T_{b v}-T_{b h}\right) / 1 / 2\left(T_{b v}+T_{b h}\right)\right)$. This quantity is independent of thermal temperature and emphasizes the differences between horizontal and vertical polarization.

\section{Description of the experiments}

Due to the importance of orographic effects that are able to modify the water balance mechanism, influencing or creating precipitating clouds, particular attention was given to soil moisture retrieval on hilly and pede- mountain areas (Bacchi et al., 1996). Therefore, two different hilly areas were taken into consideration in two remote sensing campaigns carried out in 1999 and 2000, respectively.

- The first experiment was carried out in the Toce river valley within the largescale phase in the Alpine regions of the Mesoscale Alpine Program (MAP), during the period September 1st-November 15th 1999. This was devoted mainly to the study of intense meteorological phenomena due to orography, in particular, the flooding caused by intense and unforeseen rainfall in mountain regions (Bougeault et al., 2001; Paloscia et al., 2001(a); Ranzi 2000).

- The second experiment (CHEERS: Cerbaia Hydrological Experiment for Earth Remote Sensing), carried out on the basin of the Pesa river in Tuscany, in February and May 2000, was focused on the retrieval of soil moisture and surface roughness using multifrequency microwave data (Paloscia et al., 2001(b)).

The equipment used in both the experiments was made up of: three IROE microwave radiometers (L, C and X bands)

Table 1. Characteristics of IROE microwave radiometers

\begin{tabular}{llcllll}
\hline Bands & Frequency/Wavelength & Pol & Theta & Bandwidth & Antenna & HPBW \\
\hline L & $1.4 \mathrm{GHz} / 21 \mathrm{~cm}$ & V or H & $15-20^{\circ}$ & $30 \mathrm{MHz}$ & Microstrip & $\begin{array}{l}3 \mathrm{~dB}=20^{\circ} \\
20 \mathrm{~dB}=60^{\circ}\end{array}$ \\
$\mathrm{C}$ & $6.8 \mathrm{GHz} / 4.5 \mathrm{~cm}$ & $\mathrm{~V} / \mathrm{H}$ & $15-20^{\circ}$ & $500 \mathrm{MHz}$ & Conical horn & $\begin{array}{l}3 \mathrm{~dB}=18^{\circ} \\
20 \mathrm{~dB}=40^{\circ}\end{array}$ \\
& & & & & $3 \mathrm{~dB}=20^{\circ}$ \\
$\mathrm{X}$ & $10 \mathrm{GHz} / 3 \mathrm{~cm}$ & $\mathrm{~V} / \mathrm{H}$ & $20^{\circ} \& 50^{\circ}$ & $500 \mathrm{MHz}$ & Conical horn & $20 \mathrm{~dB}=40^{\circ}$ \\
\hline
\end{tabular}


(Table 1), one thermal infrared radiometer $(8-14 \mu \mathrm{m})$, one TV camera, used as a reference, and a PC-controlled data acquisition system.

\section{GROUND TRUTH METHODS}

To analyse the relationships between radiometric measurements and ground truth, soil and vegetation parameters were measured directly in the test areas simultaneously with the flights. The parameters measured were: plant water content (PWC, in $\mathrm{kg} \mathrm{m}^{-2}$ ), soil moisture $\left(\mathrm{SMC}\right.$, in $\left.\mathrm{g} \mathrm{cm}^{-3}\right)$, and soil surface roughness $(s$, in $\mathrm{cm})$ at the different test-sites.

- Soil moisture content (SMC) was measured by using both destructive and non-destructive methods. The destructive method consisted of gathering samples of soil at a depth of 0-5 $\mathrm{cm}$ with a probe of known volume. The moist samples were weighed with a portable scale and dried in a microwave oven. By using wet $\left(\mathrm{W}_{1}\right)$ and dry $\left(\mathrm{W}_{2}\right)$ soil masses and the volume $(\mathrm{V})$, both volumetric ( $\mathrm{SMCv})$ and gravimetric ( $\mathrm{SMCg}$ ) soil moisture values can be calculated:

$$
\mathrm{SMCV}=\left[\left(\mathrm{W}_{1}-\mathrm{W}_{2}\right) / \mathrm{V}\right] \times 100
$$$$
\mathrm{SMCg}=\left[\left(\mathrm{W}_{1-}-\mathrm{W}_{2}\right) / \mathrm{W}_{2}\right] \times 100
$$

Nondestructive methods used during these experiments were the soil dielectric constant measurements using a probe at L-band in the Cerbaia area, and several TDR probes (Time Domain Reflectometry) in the Toce Valley (Menziani et al., 2001).

It is important that a sufficient number of samples be taken to capture water content variations due to soil texture, topography, cultivation (ridge, furrow) and the stage in the drying cycle. In general, for rather homogeneous agricultural fields of about 2-4 ha in area, experience accumulated in various experimental campaigns indicates that 4-6 sample measurement sites per field and 3-4 SMC measurements at each site can be sufficient. The soil texture was silty-loam in Cerbaia and less homogeneous in the Toce Valley, where medium-texture soils were close to silty-clay ones.

- Vegetation biomass was described through the measurement of plant water content ( $\mathrm{PWC}$, in $\mathrm{kg} \mathrm{m}^{-2}$ ), obtained by weighing the plant samples and drying them in a oven. The plant water content was the difference between the wet and dry plant weight. Also in this case, for rather homogeneous agricultural fields, 3-4 plant samples (or the stems of an area of $25 \times 25 \mathrm{~cm}^{2}$ ) were collected at 4-6 sites for each field.

- The soil surface roughness, expressed by means of the standard deviation of the surface heights $(s)$, was usually measured using a needle profilometer placed on the soil surface. The pictures of the soil profiles were digitised to determine this statistic.

\section{THE TOCE VALLEY EXPERIMENT}

Several types of measurement were carried out in the catchment upstream of the Lago Maggiore Miorina dam $\left(6599 \mathrm{~km}^{2}\right)$, in Switzerland and Italy. This basin is drained by the Ticino, Maggia, Verzasca and Toce rivers and was chosen mainly for the large magnitude of the rainfall and runoff events. With a mean specific maximum annual flow of $0.8 \mathrm{~m}^{3} \mathrm{~s}^{-1} \mathrm{~km}$, the Toce basin has, in fact, the highest floods in the area, and one of the highest in the Alps, for basins of similar size (Ranzi, 2000). The microwave experiment was focused on the Toce basin, in Italy, in the stretch from Villadossola to Anzola.

Flights were performed on September $23^{\text {rd }}$ using 2 microwave radiometers ( $\mathrm{L}$ and $\mathrm{C}$-bands), at an incidence angle $(\theta)=15-20^{\circ}$, and on October $28^{\text {th }}$ and $29^{\text {th }}$, by adding the X-band channel operating at two different incidence angles, $\theta=15-20^{\circ}$ and $\theta=50^{\circ}$, to the sensor package. the ban data were used to obtain further information on the vegetation biomass. In this area, only a few bare soils were present at that time, and vegetation was represented mainly by grass and corn fields in different stages of ripening. Rainfall occurred on the days preceding the flights, especially in October. Thus, the soils were generally moist, with a soil moisture content higher than $15-20 \%$. Weather was variable, with clear-sky and cloudy conditions alternating .

\section{THE CHEERS EXPERIMENT}

This experimental campaign was carried out on the Cerbaia agricultural area (Tuscany) in February and May 2000. The set of radiometers was installed onboard two ultra-light aircraft (Fig. 1). The measurements were repeated for two different angles of incidence: $\theta=20^{\circ}$ and $50^{\circ}$.

The Cerbaia site is in the Pesa River Basin, located on the hydrographic left of the Arno River, and elongated in a NWSE direction. The site is an agricultural hilly area, representative of the landscape and climate of central Italy. On the slopes there are mainly olive-groves and vineyards; some forests are present on the top of the hills and on the steepest slopes. The remaining part is flat, with the alluvial wetland of the Pesa River, agricultural fields (growing wheat, barley, corn, oil seed, sunflower, alfalfa, sorghum, etc.) and urbanisation. Since 1988 many remote sensing experiments were also carried out by IFAC and other institutes within the framework of international campaigns 

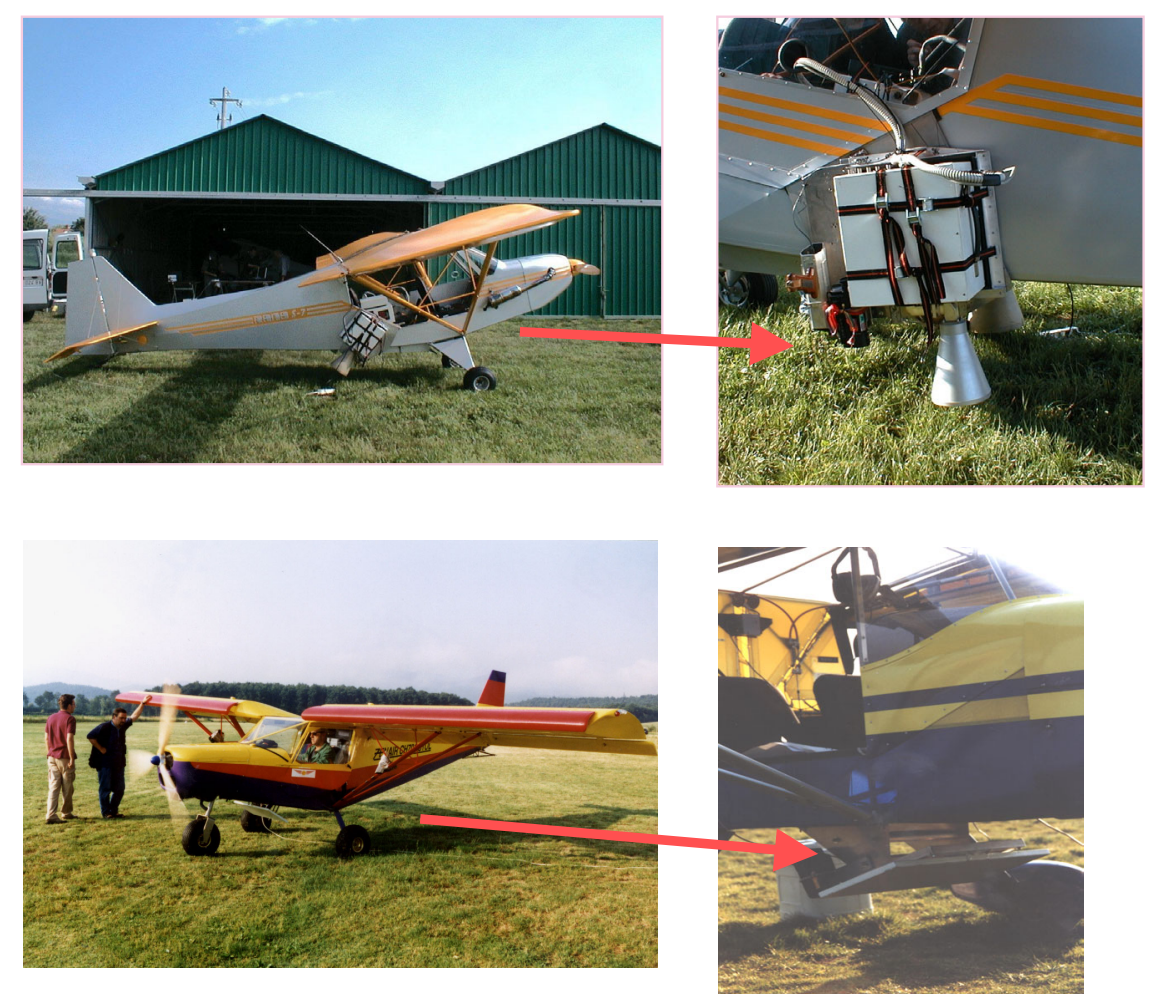

Fig. 1. The installation of the IROE sensors onboard the two ultra-light airplanes: showing the Cband radiometer (top) and the flat microstrip antenna of L-band radiometer (bottom).

(Canuti et al., 1991; Macelloni et al., 1999; Paloscia et al., 1993a; Paloscia et al., 1999).

In February, most fields were bare soil, some of them already seeded with wheat and others prepared for the spring sowing. Wheat plants had just sprouted and their plant water content (PWC) was very small, $0.1 \mathrm{~kg} \mathrm{~m}^{-2}$. Heavy rainfalls occurred before February14th and therefore soil moisture content was rather high, at least in the deeper soil layer. Due to the windy weather and the seeding works carried out in the fields, the very first layer of soil was dry (10\%) and strongly porous. In the underlying layers, soil was more compact, with a higher moisture (17-18\%) (Paloscia et al., 2001(b)). In May, the wheat fields were well developed, with an average PWC of $2-3 \mathrm{~kg} \mathrm{~m}^{-2}$. Many fields were still bare soil, just seeded with spring crops (sunflower, alfalfa and corn). The weather was dry and consequently the fields were rather arid with an average SMC less than $10 \%$.

\section{Experimental results}

\section{SMC MEASUREMENTS AT L-BAND}

Unfortunately, in the experiment on the Toce valley, electromagnetic interferences, due to radio links and other artificial e.m. sources in the area, strongly affected L-band emission, hampering a mapping of soil moisture at this frequency. Only a few points, retrieved in the Pieve Vergonte area, were available with a reasonable value of $\mathrm{T}_{\mathrm{b}}$ (Paloscia et al., 2001(a)). Data gathered at the other frequencies (C and $\mathrm{X}$ ) were fine and used in the following sections for correcting vegetation effects on SMC measurements.

Good results at L-band were obtained in the CHEERS experiment on the Cerbaia area: in this case, the measurements confirmed the sensitivity of this band to soil moisture. Figure 2 shows the $\mathrm{L}$ band brightness temperature, $\mathrm{T}_{\mathrm{b}}$, collected at $\mathrm{H}$ pol., and $\theta=20^{\circ}$ in February 2000. The range of $T_{b}$ is between about 200 and $260 \mathrm{~K}$ showing a significant range of variations, much more related to the different values of SMC than to any other features of individual fields. To extract a map of SMC from $T_{b}$, the following regression equations obtained for bare and vegetated soils in previous experiments (Paloscia et al., 1993b) were used:

- Bare soils $\rightarrow \mathrm{Tn}=0.917-0.0087 * \mathrm{SMC}$

- Vegetated soils $\rightarrow \mathrm{Tn}=0.968-0.0046 * \mathrm{SMC}$

Note that the presence of vegetation leads to a slight decrease in sensitivity, of about $0.009 / \% \mathrm{SMC}$, roughly 


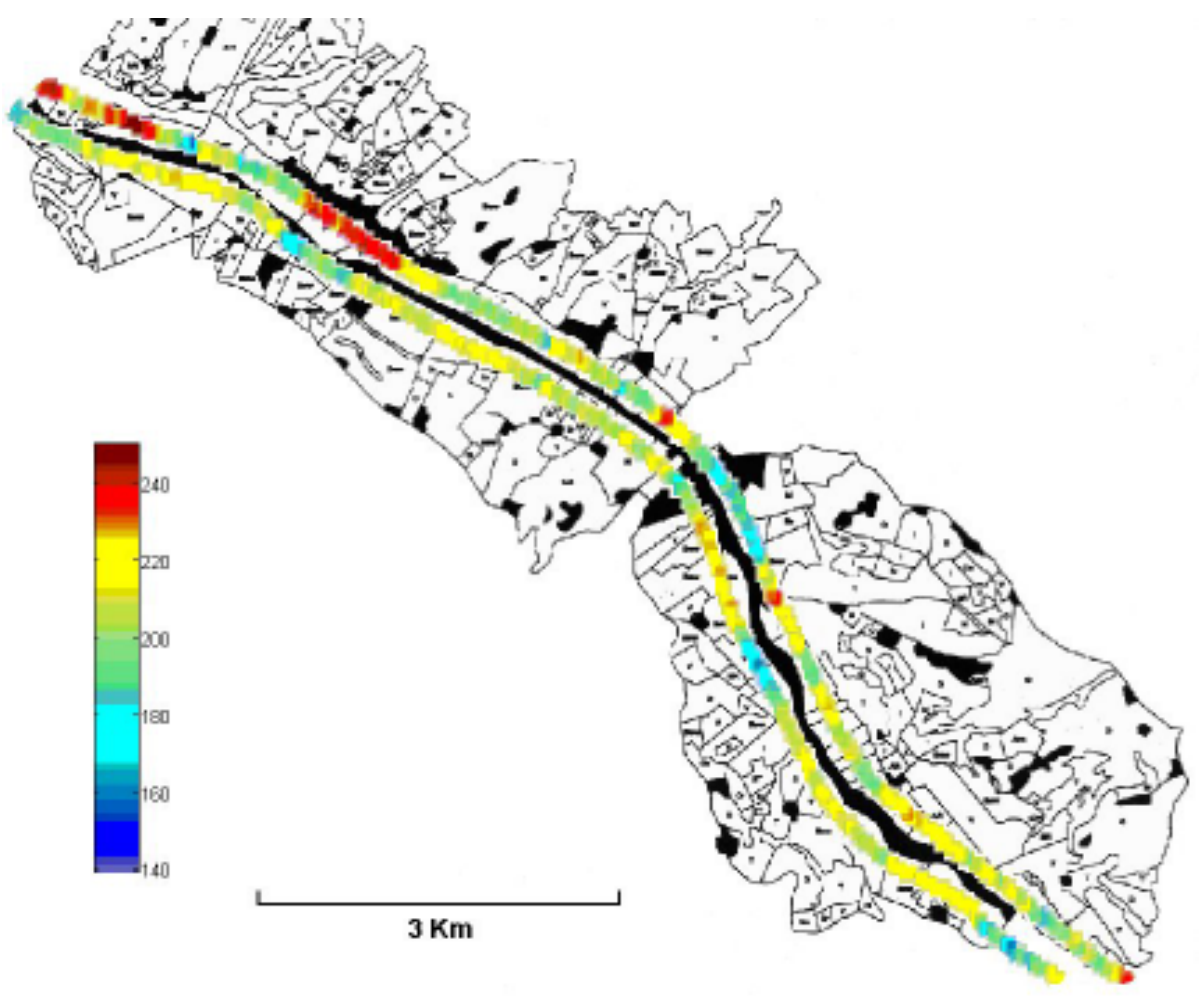

Fig. 2. Map of brightness temperature, Tb, at L-band $\left(H\right.$ pol., $\left.q \delta=20^{\circ}\right)$ collected on Cerbaia area on February 2000.

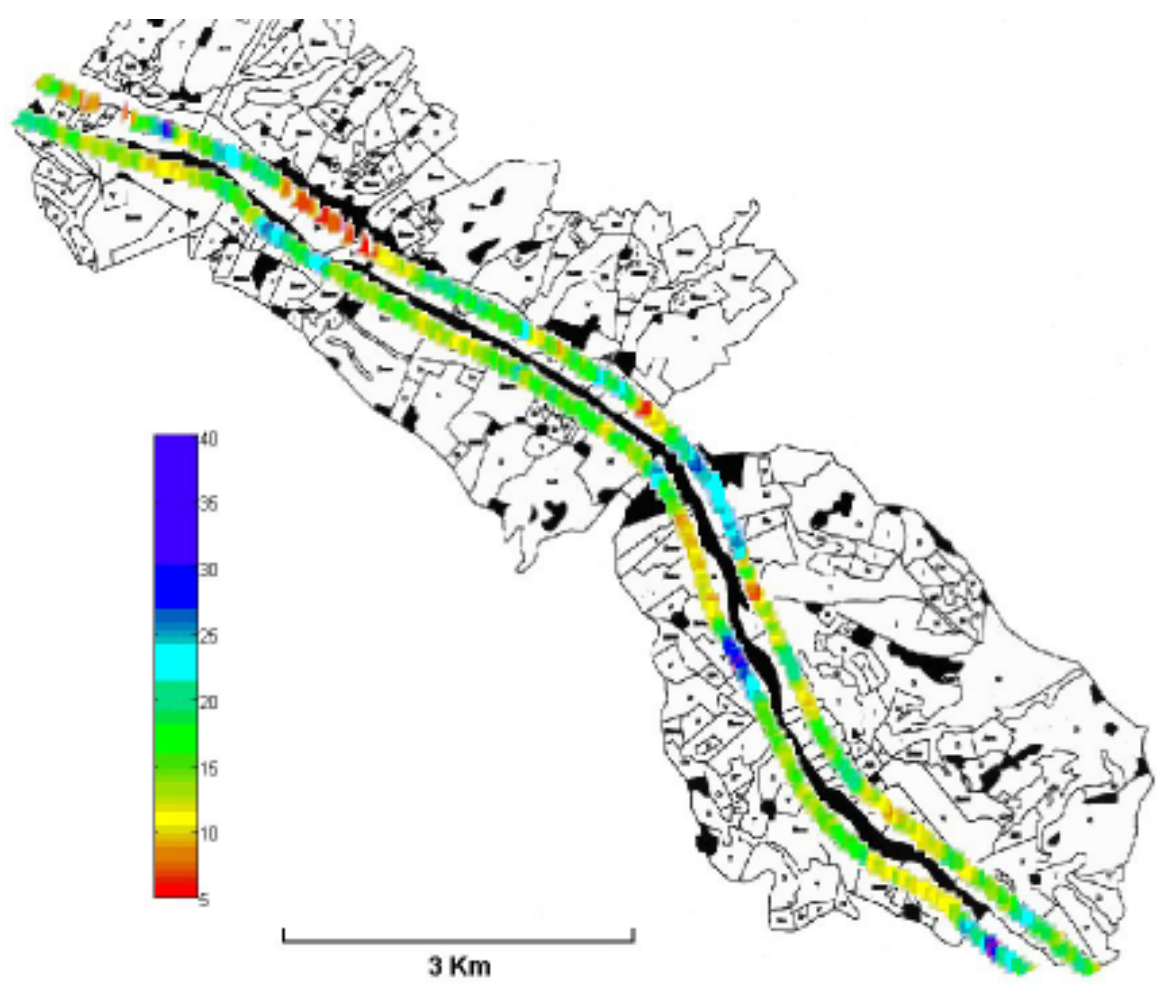

Fig. 3. Map of estimated SMC\% at L-band over the Cerbaia test site. 


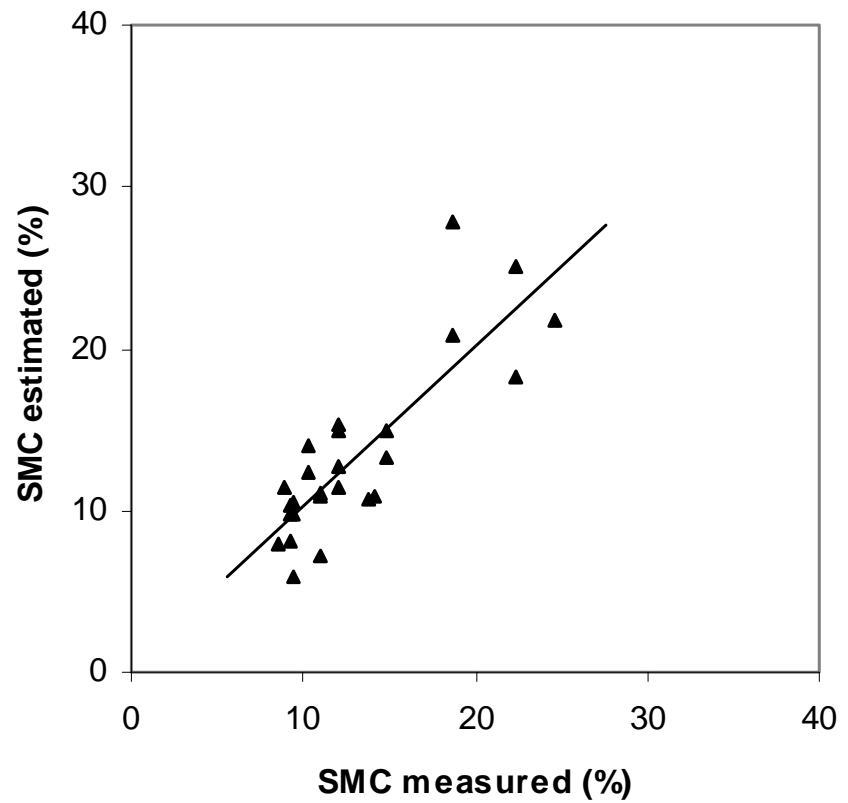

Fig. 4. SMC\% estimated at L-band (H pol., $q \partial=20^{\circ}$ ) using the algorithm described in Eqn. 2 vs. SMC\% measured on ground. The line represents the regression line: $S M C e=0.987 S M C m+0.426$ $(R=0.84)$.

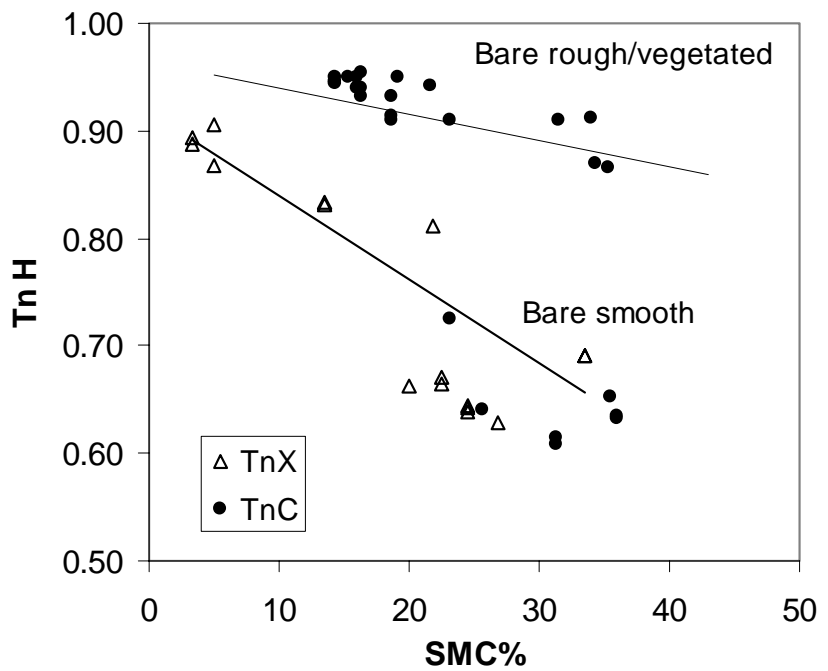

Fig. 5. Tn data $\left(H\right.$ pol., $\left.\theta=20^{\circ}\right)$ measured at $C$-and $X$-bands on bare and vegetated soils as a function of SMC\% of the first $0-2.5 \mathrm{~cm}$. The lower line represents the regression of different data sets collected by using IROE sensor at $C$ - and X-bands on smooth bare soils of Cerbaia and Toce areas (lower cluster), whereas the upper line was obtained from literature (Jackson et al., 1984) for vegetated soils at $C$-band. Data of the upper cluster have been collected at C-band on both Cerbaia and Toce bare-rough and vegetated soils. $(\bullet=C$-band, $\Delta=X$-band). corresponding to $2.5 \mathrm{~K} / \% \mathrm{SMC}$ for bare soils and $0.005 /$ $\%$ SMC $(\approx 1.5 \mathrm{~K} / \% \mathrm{SMC})$.

Since most soils were bare in February, Eqn. (2) was inverted, and $T_{b}$ values were converted in $T_{n}$ using the thermal infrared data $\left(\mathrm{T}_{\mathrm{n}}=\mathrm{T}_{\mathrm{b}} / \mathrm{T}_{\mathrm{ir}}\right)$. Thus, SMC values were retrieved from the $\mathrm{T}_{\mathrm{b}}$ map of Fig. 2, and a map of SMC for the area of Cerbaia was drawn. The result is shown in Fig. 3 which shows the variations in SMC along the river. The comparison between estimated and ground measured SMC in Fig. 4, shows a good correlation, with a correlation coefficient, $\mathrm{R},=0.84$ and a Standard Error of Estimate, SEE, $=3$.

\section{SMC MEASUREMENTS AT C- AND X-BAND}

In Fig. 5, $\mathrm{T}_{\mathrm{n}}$ data measured on both the Cerbaia and Toce areas at $\mathrm{C}$ - and $\mathrm{X}$ - bands $\left(\mathrm{H}\right.$ pol., $\left.\mathrm{q}=15-20^{\circ}\right)$ on bare and smooth soils are shown $v$. SMC of the first $2.5 \mathrm{~cm}$ layer of soil (lower cluster). It should be noted that data in the diagram represent the $T_{b}$ and SMC values averaged for each field. The sample dimensions for the $T_{b}$ was about $60 \mathrm{~m} \times$ $60 \mathrm{~m}$, and the number of samples depends on the field dimensions, while the procedure for the SMC ground measurements has been described above. This diagram shows that $\mathrm{T}_{\mathrm{n}}$ values collected at $\mathrm{C}$ - and $\mathrm{X}$-bands on bare and smooth fields are comparable with those obtained at Lband, showing again a sensitivity to SMC of the order of about $0.008 / \%$ SMC $(2.4 \mathrm{~K} / \%$ SMC) typical of rather smooth soils without vegetation cover (Jackson et al., 1984; Paloscia et al., 1993; Paloscia et al., 2001(a)). Figure 5 also shows that the sensitivity of $\mathrm{T}_{\mathrm{n}}$ at $\mathrm{C}$-band $\left(\mathrm{H}\right.$ pol., $\left.\theta=20^{\circ}\right)$ to SMC of bare-rough and vegetated soils is much lower (upper cluster). Data at X-band are not shown in this cluster, since the sensitivity to SMC at this frequency is completely blinded by surface roughness and vegetation. Indeed it is unmistakable that the presence of vegetation, as well as the soil surface roughness, strongly reduces the sensitivity to SMC of $T_{n}$ at the higher frequencies. The lines drawn on the diagram represent the regression line of the experimental data at $\mathrm{C}$ - and $\mathrm{X}$-bands for the lower cluster, and the following correlation equation, valid at C-band for vegetated fields (upper cluster), found in (Jackson et al., 1984):

$$
\mathrm{T}_{\mathrm{nC}}=0.964-0.0024 * \mathrm{SMC}(\mathrm{R}=0.81)
$$

It can be seen that the sensitivity to SMC in the latter case decreases dramatically to a value of about $0.0024 / \% \mathrm{SMC}$ (corresponding to $0.7 \mathrm{~K} / \% \mathrm{SMC}$ ).

To evaluate the capabilities of remote sensing techniques in Earth observation on a large scale, it is necessary to consider that the L-band is not available from current satellite 
sensors and that, moreover, satellite sensors usually look at the Earth's surface with high incidence angles. Thus, research has been focused on the potential of existing sensors and, in particlar, on the sensitivity of the C-band emission at $50^{\circ}$ of the incidence angle to the surface features.

As already said, the vegetation cover strongly influences the microwave emission at this high incidence angle and affects the SMC retrieval. These vegetation effects are particularly noticeable in Fig. 6 which shows the relationship between $\mathrm{T}_{\mathrm{b}}$ at $\mathrm{C}$-band ( $\mathrm{H}$ pol., and $\theta=50^{\circ}$ ) and $\mathrm{SMC}$ of the first $2.5 \mathrm{~cm}$ of soil. Here, experimental points, which are rather spread out, have been separated into three groups according to their vegetation cover: (a) bare soils, (b) lowvegetated, and (c) well- vegetated fields, and fitted by the following regression lines, respectively:
(a) $\mathrm{T}_{\mathrm{b}}=279-0.27 * \mathrm{SMC}$
$(\mathrm{R}=0.98)$,
(b) $\mathrm{T}_{\mathrm{b}}=289-2.1 * \mathrm{SMC}$
$(\mathrm{R}=0.89)$, and
(c) $\mathrm{T}_{\mathrm{b}}=295-1.34 * \mathrm{SMC}$
$(\mathrm{R}=0.90)$.

To correct the SMC retrieval for vegetation effects, a multifrequency algorithm was proposed by Macelloni et al., 2000 and Paloscia et al., 2001c. The algorithm is based on the sensitivity of the Polarization Index, PI, at X-band to the vegetation biomass. Indeed, the PI at $X$ band and $\theta \approx 50^{\circ}$ well describes the vegetation growth, and may be related to the PWC (or Leaf Area Index, LAI) of some agricultural crops (e.g. corn, alfalfa, sugar beet and sunflower) through a semi-empirical model described in Pampaloni and Paloscia (1986) and Paloscia and Pampaloni (1988). This model

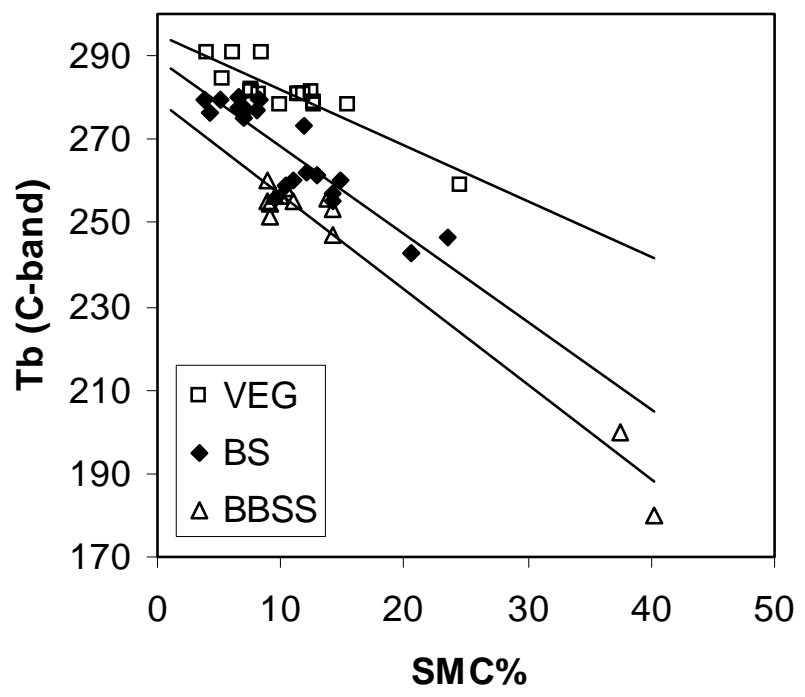

Fig. 6. $T_{b}$ at $C$-band ( $H$ pol., $\theta=50^{\circ}$ ) v. $S M C \%$ of the first $0-2.5 \mathrm{~cm}$ layer for different types of surfaces: bare soils (BBSS), low (BS) and well-vegetated fields (VEG). relates PI and PWC through the following equation:

$$
\operatorname{PI}(\mathrm{PWC}, \mu)=\operatorname{PI}(0, \mu) /\left[(1+\mathrm{PWC})^{(\mathrm{k} / \mu \sqrt{ } \lambda)}\right]
$$

where: $\mathrm{PI}(0)$ is the PI from bare soil (assumed to be equal to $\left.50^{*} 10^{-3}\right), \mu=\cos \theta$ (incidence direction), $\lambda=$ wavelength (m), and $\mathrm{k}$ is a factor depending on the crop type and ranging between $0.1 \mathrm{~m}^{1 / 2}$ for sunflower and $0.4 \mathrm{~m}^{1 / 2}$ for alfalfa.

Figure 7 shows the comparison between the model described in Eqn. (5) and the measured values of PI over some crops (i.e. corn, alfalfa, sunflower and sugarbeet), characterised by different values of PWC. Experimental data were collected at different agricultural sites in Italy and in the Toce area.

On the basis of these results, it can be assumed that PI at $\mathrm{X}$-band, since it is able to discriminate between several levels of vegetation biomass, can be related to the slope $(\mathrm{N})$ and the intercept $(M)$ of the regression lines between $T_{b}$ at $\mathrm{C}$-band and SMC represented in Fig.6, which can be described by the following generic equation:

$$
\mathrm{SMC}=\mathrm{M}+\mathrm{N} * \mathrm{~Tb}_{\mathrm{C}}
$$

As the soil is covered by vegetation, the slope $(\mathrm{N})$ and the intercept (M) of the regression line change and can be expressed as a function of the Polarization Index at X-band:

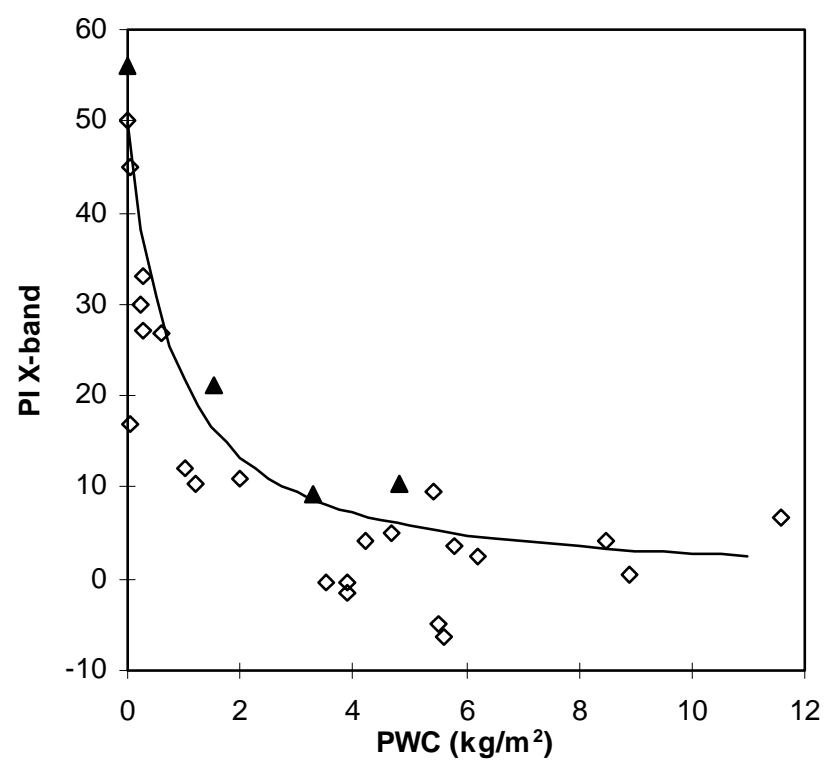

Fig. 7. $P I$ at $X$-band $\left(\theta=50^{\circ}\right)$ as a function of $P W C\left(\mathrm{~kg} \mathrm{~m}^{-2}\right)$ of some agricultural fields. Points represent the experimental data collected on several crops $(\diamond:$ corn, alfalfa, sugarbeet and sunflower; $\Delta:$ corn in different ripening stages in the Toce area). The continuous line represents the semi-empirical model of Eqn. 5 (Paloscia and Pampaloni, 1988) 


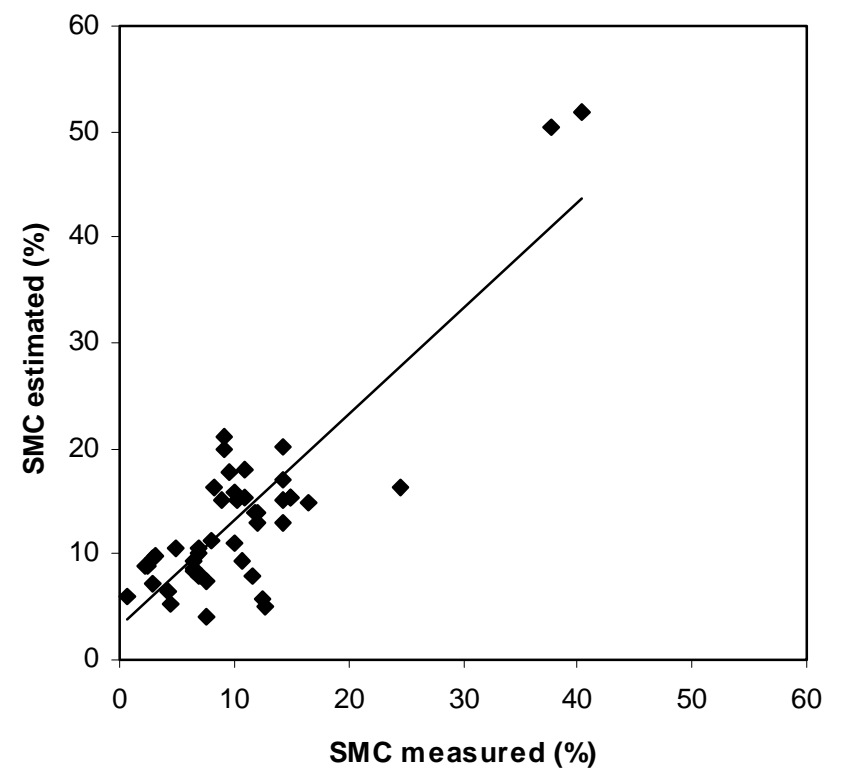

Fig. 8. SMC\% estimated using the algorithm described in Eqn. 9, v. $S M C \%$ measured on ground. The line represents the regression equation: $S M C e=1.04 S M C m+2.56(R=0.86)$.

$$
\begin{aligned}
& \mathrm{N}=3.81 \mathrm{PI}_{\mathrm{X}}-0.52 \\
& \text { and } \\
& \mathrm{M}=153.4 \exp \left(-9.03 \mathrm{PI}_{\mathrm{X}}\right)
\end{aligned}
$$

Substituting these relationships in Eqn. (6), more adequate coefficients can be chosen for the regression line of SMC retrieval, which becomes:

$$
\begin{array}{r}
\mathrm{SMC}=\left[\left(153.4 \exp \left(-9.03 \mathrm{PI}_{\mathrm{X}}\right)\right]+\right. \\
{\left[\left(3.81 \mathrm{PI}_{\mathrm{X}}-0.52\right) \mathrm{Tb}_{\mathrm{C}}\right]}
\end{array}
$$

The result obtained from this algorithm is shown in Fig. 8, where the SMC computed from $\mathrm{C}$ - and $\mathrm{X}$-band measurements is represented as a function of SMC measured on the ground. The $\mathrm{R}$ for all data $=0.86$, and the $\mathrm{SEE}=4$. As shown in the figure, the proposed algorithm allows a reduction in the dispersion of points observed in Fig. 6 (especially in the SMC range between 5\% and 20\%) and also the retrieval of SMC at high incidence angles.

\section{SOIL MOISTURE PROFILE RETRIEVAL}

During these investigations, it was confirmed that the soil depth affected by microwave emission depends on the observation wavelength and that is of the order of some centimetres $(\geq 5 \mathrm{~cm})$ at L-band; at higher frequencies, the sensitivity is limited to the moisture of soil layers closer to the surface.

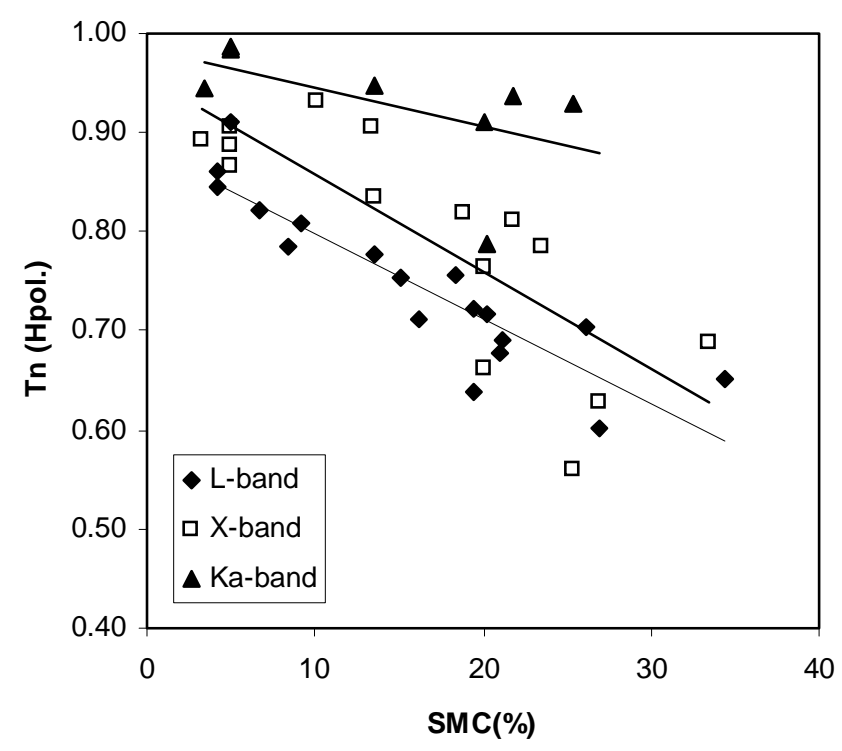

Fig. 9. Tn at L, X and Ka bands vs. the SMC\% of the layer thickness which mainly affects the emission at each frequency: 0-1 cm at Kaband, $0-2.5 \mathrm{~cm}$ at $X$-band and $0-10 \mathrm{~cm}$ at L-band.

These remarks lead to the hypothesis that multi-frequency observations could retrieve the soil moisture profile. To investigate this potential of microwave observations, data sets at L-, X- and Ka- bands (1.4, 10, and $37 \mathrm{GHz}$ ) gathered during an experiment carried out in 1988 at different incidence angles, from a sandy soil sample placed in a tank of $120 \times 120 \times 70 \mathrm{~cm}^{3}$, have been analysed (Paloscia et al., 1993). Microwave instruments were installed on a mechanical interface at an appropriate distance, which guaranteed that the main lobes of the antenna were contained in the target. For the L-band system a different antenna with a narrow main lobe was used. This approach gave the possibility of controlling some geophysical parameters and guaranteed greater precision. In field experiments, due to the dimensions of the fields themselves and the heterogeneity of the surfaces, high accuracy in measurements cannot be assured.

In Fig. $9 \mathrm{~T}_{\mathrm{n}}$ data at L-, X- and Ka-bands have been represented as a function of the SMC of the soil layer thickness which is supposed to affect naturally the emission at each frequency: $0-1 \mathrm{~cm}$ at Ka-band, $0-2.5 \mathrm{~cm}$ at Xband and $0-5 / 0-10 \mathrm{~cm}$ at L-band. The regression lines obtained at each frequency, along with their correlation coefficients, are the following:
- $\mathrm{T}_{\mathrm{n}}$ at L-band
SMC 0-10 cm
$(\mathrm{R}=0.94)$
- $\mathrm{T}_{\mathrm{n}}$ at X-band
$\mathrm{SMC} 0-2.5 \mathrm{~cm} \quad(\mathrm{R}=0.80)$ 
Profile 1

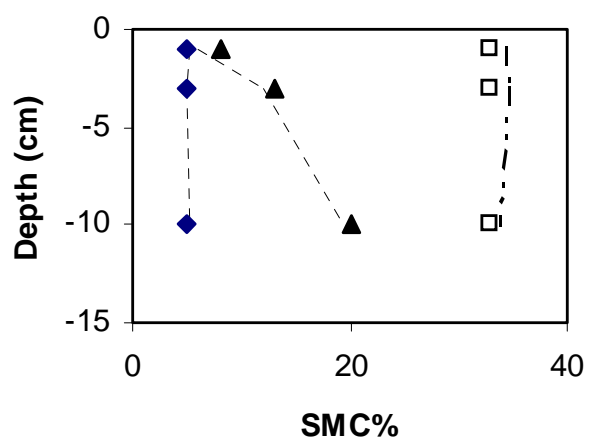

Profile 2

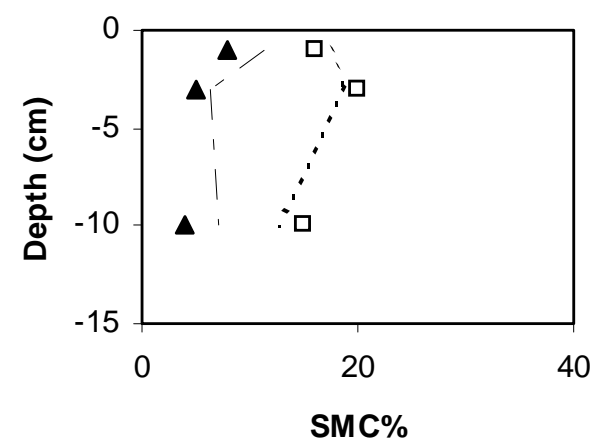

Fig. 10. The SMC profiles retrieved using the neural network (ANN2), trained using IEM data and experimental data, compared with the ground measured SMC profiles at L, X and Ka bands. Points represent experimental data, lines the retrieved ones. a) SMC profile 1 and b) SMC profile 2.

$$
\text { - } \mathrm{T}_{\mathrm{n}} \text { at Ka-band } \quad \rightarrow \text { SMC } 0-1 \mathrm{~cm} \quad(\mathrm{R}=0.60)
$$

These results confirmed the strong sensitivity of L-band to SMC of a layer of at least $5 \mathrm{~cm}$ regardless of the surface roughness. Approximately the same results were obtained at X-band but only for a SMC of 0-2.5 cm and on smooth surfaces, because the sensitivity to SMC decreased as surface roughness increased. Ka-band emission was less sensitive to SMC and much more affected by the surface roughness. A slight correlation was found only for SMC measured in the first centimetre.

In the soil sample, two types of moisture profiles were identified: (1) profiles characterised by constant or increasing values of soil moisture with depth and (2) profiles with decreasing values of soil moisture with depth, or with a maximum of a few centimetres under the surface.

To retrieve SMC at different depths $(0-1 \mathrm{~cm}, 0-2.5 \mathrm{~cm}$, $0-10 \mathrm{~cm}$ ) from the multi-frequency data set of $\mathrm{T}_{\mathrm{n}}$ (in $\mathrm{H}$ polarisation), an Artificial Neural Network (ANN) was implemented and trained in order to reproduce the soil moisture at different depths. The ANN architecture used was a Multi Layer Perceptron (MLP), i.e. a feed-forward neural network, which has one hidden layer of 7 neurons between the input and output layers. The training phase was performed by using the back-propagation (BP) learning rule,

Table2. Correlation coefficients $(\mathrm{R})$ of the regressions between SMC retrieved with the ANN1 and ANN2 and SMC ground measured.

\begin{tabular}{lll}
\hline Bands & $R(A N N 1)$ & $R(A N N 2)$ \\
\hline $\mathrm{L}$ & 0.75 & 0.94 \\
$\mathrm{X}$ & 0.71 & 0.87 \\
$\mathrm{Ka}$ & 0.76 & 0.94 \\
\hline
\end{tabular}

first using the data set generated by the IEM only (ANN1) and later on using both IEM and experimental data 16 (ANN2). In the latter case, the measured data sets used for training the ANN2 were not used for the inversion.

The correlation coefficients $(\mathrm{R})$ of the regressions between the SMC retrieved with ANN1 and ANN2 from data at L-, $\mathrm{X}$ - and Ka-bands and the ground measured SMC are summarised in Table 2. Note that by training with the IEM data only (ANN1), the results are not very good whereas a much better agreement between measured and retrieved data is obtained by using both the IEM model and the experimental data (ANN2).

The retrieved and measured profiles of SMC are shown in Fig. 10. Two types of SMC profiles have been separated: SMC constant or increasing with depth (a) and SMC decreasing with depth or irregular (b). It can be seen that the retrieved profiles reproduce the measured ones fairly well although with some discrepancies in the case of (b), where the trend of SMC with depth is irregular.

\section{Conclusions}

Experimental results have confirmed the sensitivity of microwave emission to the moisture of the soil. From analysis of the collected data sets, L-band emission has been found to be correlated well to SMC of a rather deep soil layer. A soil moisture map of the Cerbaia area was obtained from L-band measurements. As expected, C-band microwave brightness was sensitive to the surface SMC and affected more by the presence of vegetation and roughness of soil, especially at the high incidence angles that are commonly used in satellite installations. However, the sensitivity of the X-band Polarization Index to vegetation biomass can assist in the retrieval of the soil moisture from C-band data. Indeed, the retrieval algorithm, based on the 
measurement $\mathrm{T}_{\mathrm{b}}$ in $\mathrm{H}$ pol. at $\mathrm{C}$-band $\left(\theta=50^{\circ}\right)$ and PI at $\mathrm{X}$ band, has given satisfactory results.

The analysis of multifrequency L-, X- and Ka-band data, collected on a sample of sandy soil together with accurate ground truth measurements of soil moisture and temperature at different depths, has allowed microwave emission at certain wavelengths to be related to a corresponding sampling depth. The use of these data with IEM simulations in an artificial neural network made it possible to retrieve vertical profiles of soil moisture.

These results led to the conclusion that the use of airborne microwave radiometers make possible extensive measurements of the moisture conditions of a river basin, especially before and after heavy rainfalls, and can contribute significantly to improving the knowledge of the hydrological balance and evaluating the risk of flood events.

\section{Acknowledgements}

This work was partially supported by CNR "Progetto Strategico MAP-SOP", by ASI (Italian Space Agency), and by NASDA contract A2ARF003

\section{References}

Bacchi, B., Ranzi, R. and Borga, M., 1996. Recognition of the statistical character of spatial patterns of rainfall cells. $J$. Geophys. Res., 101D, 26277-26286.

Binder, P. and Schär, C., 1996. The Mesoscale Alpine Programme MAP: Design Proposal. Second Edition. MAP Programme Office, c/o Meteo Swiss, Zurich, Switzerland . 77pp.

Bougeault, P. and Binder, P., 2002. The Mesoscale Alpine Programme. WMO Bulletin, 51, 14-17.

Bougeault, P., Binder, P., Buzzi, A., Dirks, R., Houze, R., Kuettner, J., Smith, R.B., Steinacker, R. and Volkert, H., 2001. The MAP Special Observing Period. Bull. Amer. Meteorol. Soc., 82, 433-462.

Canuti, P., Focardi, P., Garzonio, C., Rodolfi, G. and Vannocci, P., 1986. Slope stability mapping in Tuscany, Italy. Int. Geomorphology, part I, Wiley. 231-240.

Canuti, P., d'Auria, G., Pampaloni, P. and Solimini, D., 1991. MAC91 on Montespertoli, and experiment for Agro-hydrology. Proc. IGARSS'91, Espoo, Finland, vol. IV, 1744-1746. (IEEE NE91CH2971-0, Lib. of Congress 91-864187).

Choudhury, B., Schmugge, T., Chang, A. and Newton, R., 1979. Effect of surface roughness on microwave emission from soils. J. Geophys. Res., 84, 5699-5706.

Dawson, M.S., 1993. Surface parameter retrieval using fast learning neural networks. Remote Sensing Rev., 7, 1-18.

Fung, A.K., 1994. Microwave scattering and emission models and their applications. Artech House, Norwood, MA, USA.

Haefner, H. and Pampaloni P., 1992. Water Resources. Inter. J. Remote Sensing, 13, 1277-1303.

Hornik, K., 1989. Multilayer feedforward network are universal approximators. Neural Networks, 2, 359-366.

Jackson, T., Schmugge, T. and Wang, J., 1982. Passive microwave remote sensing of soil moisture under vegetation canopies. Water Resour. Res., 18, 1137-1142.
Jackson, T., Schmugge, T. and O’Neill, P., 1984. Passive microwave remote sensing of soil moisture from an aircraft platform. Remote Sensing Environ., 14, 135-151.

Lampart, G., Bach, H., Braun, M., Taschner, S., Ludwig, R. and Mauser, W., 2000. Application of remote sensing and water balance modelling in alpine areas for flood hazard forecasting and control. Workshop on advanced techniques for the assessment of natural hazards in mountain areas, SAI, JRC, June 2000.

Macelloni, G., Paloscia, S., Pampaloni, P., Sigismondi, S., De Matthaeis, P., Ferrazzoli, P., Schiavon, G. and Solimini, D., 1999. The SIR-C/X-SAR experiment on 19 Montespertoli supersite: the sensitivity to hydrological parameters. Int. J. Remote Sens., 20, 2597-2612.

Macelloni, G., Paloscia, S., Pampaloni, P., Ruisi, R. and Susini, C., 2000. Airborne microwave radiometer measurements on agricultural fields. In: Microwave Radiometry of Earth's Surface and Atmosphere, P. Pampaloni and S. Paloscia (Eds.), VSP Press, Utrecht, The Netherlands. 59-69.

Menziani, M., Pugnaghi, S., Pilan, L., Santangelo, R. and Vincenzi, S., 2001. TDR soil moisture measurements at Lago Maggiore MAP target area: preliminary results, Phys. Chem. Earth, Part B, 26, 431-436.

Paloscia, S., 1995. Microwave emission from vegetation. In: Remote Sensing of Land-Atmosphere Interactions, B. Choudhury, Y. Kerr, E. Njoku and P. Pampaloni (Eds.), VSP Press, Utrecht, The Netherlands. 357-374.

Paloscia, S., and Pampaloni, P., 1988. Microwave polarization index for monitoring vegetation growth. IEEE Trans. Geosci. Remote Sensing, 26, 617-621.

Paloscia, S. and Pampaloni, P., 1992. Microwave vegetation indexes for detecting biomass and water conditions of agricultural crops. Remote Sens. Environ., 40, 15-26.

Paloscia, S., Pampaloni, P., Susini, C., Bechini, C., Ijjas, G., Rieger, I. and Aujeszky, L., 1993a. Microwave experiment on Montespertoli area. In: Remote Sensing for Monitoring the Changing Environment of Europe, Peter Winkler (Ed.). Balkema, Rotterdam. ISB: 9054103116 1993. 77-83.

Paloscia, S., Pampaloni, P., Chiarantini, L., Coppo, P., Gagliani, S. and Luzi, G., 1993b. Multifrequency passive microwave remote sensing of soil moisture and roughness. Int. J. Remote Sens., 14, 467-483.

Paloscia, S., Macelloni, G., Pampaloni, P. and Sigismondi, S., 1999. The potential of C- and L- band SAR in estimating vegetation biomass: the ERS-1 and JERS-1 experiments. IEEE Trans. Geosci. Remote Sensing, 37, 2107-2110.

Paloscia, S., Macelloni, G., Pampaloni, P., Ruisi, R. and Santi, E., 2001a. Microwave Soil moisture monitoring in the Toce Valley. Phys. Chem. Earth, Part B, 26, 377-381.

Paloscia, S., Macelloni, G., Pampaloni, P., Ruisi, R., and Santi, E., 2001b. CHEERS Experiment in Tuscany: a comparison between L-band and C- and X-bands capability in measuring soil moisture. Proc. Int. Geosci. Remote Sensing Symp. (IGARSS 2001), Sydney, Australia, 9-13 July 2001, vol. I, 22-24.

Paloscia, S., Macelloni, G., Santi, E. and Toshio, K., 2001c. A multifrequency algorithm for the retrieval of soil moisture on a large scale using microwave data from SMMR and SSM/I Satellites. IEEE Trans. Geosci. Remote Sensing, 39, 1655-1661.

Pampaloni, P., and Paloscia, S., 1985, Experimental relationships between microwave emission and vegetation features. Inter. $J$. Remote Sensing, 6, 315-323.

Pampaloni, P. and Paloscia, S., 1986. Microwave emission and plant water content: a comparison between field measurement and theory. IEEE Trans. Geosci. Remote Sensing, 24, 900-905. 
Pampaloni, P., Chiarantini, L., Coppo, P., Gagliani, G., Luzi, G. and Paloscia S., 1990. Sampling depth of soil moisture content by radiometric measurements at $21 \mathrm{~cm}$ wavelength: some experimental results. Inter. J. Remote Sensing, 11, 1085-1092.

Ranzi, R., 2000. Hydrological aspects in the Mesoscale Alpine Programme-SOP experiment: an overview. In: Hydrological aspects in the Mesoscale Alpine Programme-SOP experiment, B. Bacchi and R. Ranzi (Eds.).Technical Report of the University of Brescia, Department of Civil Engineering, 10, I, 1-19.

Schmugge, T., O’Neill, P. and Wang, J.,1986. Passive microwave soil moisture research. IEEE Trans. Geosci. Remote Sensing, 24, 12-22.

Shutko, A.,1982. Microwave radiometry of lands under natural and artificial moistening. IEEE Trans. Geosci. Remote Sensing, 20, $18-26$

Ulaby, F., Moore, R. and Fung, A., 1981. Microwave Remote Sensing: Active and Passive, Addison-Wesley Publication Co., Advanced Book Program/World Science Division, Readings, Massachusetts, USA.

Ulaby, F., Razani, M. and Dobson, C., 1983. Effects of vegetation cover on the microwave radiometric sensitivity to soil moisture. IEEE Trans. Geosci. Remote Sens., 21, 51-61.

Wang, J., O’Neill, P., Jackson, T. and Engman, T., 1983, Multifrequency measurements of the effects of soil moisture, soil texture and surface roughness. I.E.E.E. Trans. Geosci. Remote Sensing, 21, 44-51. 